\title{
EQUIDADE NA COMERCIALIZAÇÃO DE SOJA: UMA ANALISE COMPARATIVA DA ULTILIZAÇÃO DO HEDGE
}

Igor Mauricio Andrade da Silva, Alexandre Godinho Bertoncello

Universidade do Oeste Paulista - UNOESTE, curso de Administração, Presidente prudente, SP. E-mail: igorandradesi@hotmail.com; bertoncello@unoeste.br

\begin{abstract}
RESUMO
A soja é de grande importância para a economia nacional e mundial, no cenário atual encontra-se produções cada vez maiores, porém o início dessa cadeia produtiva muitas vezes sofre perdas, por falta de conhecimento no momento de comercializar seu produto. Grandes produtores utilizam ferramentas de proteção, mas sojicultores de médio porte normalmente não. Este trabalho teve como objetivo demonstrar para estes agricultores as formas de se proteger das oscilações de preço do mercado. Evitando assim possíveis perdas e proporcionando uma simetria de informação na comercialização da soja. Utilizou-se para a pesquisa ampla pesquisa bibliografia para dar embasamento teórico em seguida foi feita uma análise quantitativa com espaço temporal de cinco anos para demonstrar os efeitos da utilização do hedge como proteção para a comercialização da soja. Como resultado encontrado percebeu-se ganhos médios para o sojicultor de USD 1,97 por saca para aqueles que utilizaram de forma correta a ferramenta.
\end{abstract}

Palavras - Chave: Commodities, Mercado futuro, Hedge, Sojicultores.

\section{EQUITY IN THE TRADING OF SOYBEANS: A COMPARATIVE ANALYSIS OF HEDGE ULTILIZATION}

\begin{abstract}
Soy is a product of great importance to the national and global economy, in the current scenario there are growing outputs, but the beginning of this productive chain often suffers losses due to a lack of knowledge at the moment of trading the product. Large producers use protection tools, but medium-sized soy producers do not have them usually. This study aimed to demonstrate to these farmers how to protect themselves from market price fluctuations. Thus avoiding possible losses and providing a symmetry of information in the commercialization of soybeans. A bibliographical research was used to provide a theoretical basis, followed by a quantitative analysis with a time span of five years to demonstrate the effects of the use of hedge as a protection for the commercialization of soybean. As a result, we found average gains for the soybean grower of USD 1.97 per bag for those who used the tool correctly.
\end{abstract}

Keywords: Commodities, Future market, Hedge, Soy producers.

\section{INTRODUÇÃO}

As commodities são formadas por três ramificações, a Mineral; minério de ferro, petróleo, alumínio, ouro níquel, prata, a Financeira; títulos públicos de governos federais, moedas negociadas em vários mercados e as Agrícolas; milho, café, boi gordo, trigo, algodão, soja. 0 produto soja pertence à família da commodity agrícola, a palavra commodity se originou da língua inglesa que significa mercadoria.

No Brasil o complexo soja é um importante agente econômico, a produção estimada para 2017 é de 113,9 milhões de toneladas, sua cultura corresponde a 48,6\% do total nacional de grãos produzidos no pais, aproximadamente $42,5 \%$ das exportações mundiais de soja em grão pertence ao Brasil, sendo assim o maior exportador mundial, isso gera um impacto sócio econômico 
positivo para a nação, melhorando o índice de desenvolvimento nos municípios envolvidos e se tornando um fator positivo para a balança comercial do pais (CONAB, 2017).

Porém, a grande maioria dos produtores tem grande profissionalismo na produção e pouco empenho na comercialização, e para se obter ganhos em toda a operação é necessário melhorar o processo de comercialização. O método de comercialização de Operações de Derivativos é uma ferramenta financeira que supri a necessidade de proteção contra oscilações futuras nos preços dos produtos.

Reverter este cenário seria de grande importância para os sojicultores, este trabalho buscou com informação, otimizar os recursos dos sojicultores e compradores desta commodity, assim podemos diminuir a assimetria nas negociações. Como elencado neste artigo, existem diversas ferramentas de comercialização de soja que podem contribuir para que os produtores e compradores se previnam, das oscilações de preço no mercado.

No entanto supõe-se que as ferramentas mais adequadas são a utilização de Mercado futuro e Hedge, que se enquadram nos derivativos de opções. No mercado de opções são negociados direitos de compra e venda, onde podem ser negociadas ações, títulos, commodities, contratos futuros e índices, em uma data futura com preços e prazos pré-estabelecidos, gerando uma segurança para as partes envolvidas.

Desta forma, identificamos ferramentas de comercialização de soja que podem ser utilizadas pelos sojicultores a fim de obter Simetria nas Negociações, redução de custos e aumento de ganhos.

\section{BASE TEÓRICA}

Estudou-se a comercialização do ativo commodity soja, por meio de contratos de derivativo, mostrando a importância de se fazer uma comercialização assertiva, utilizando ferramentas que proporcionem segurança para com o produtor. As commodities refletem um papel econômico importante em âmbito mundial, pelo motivo que as matérias primas e produtos poucos industrializados pertencem a sua família.

Segundo o Dicionário Dicio, commodities são:

"[Economia] Tudo aquilo que, se apresentando em seu estado bruto (mineral, vegetal etc.), pode ser produzido em larga escala; geralmente se destina ao comércio exterior e seu preço deve ser baseado na relação entre oferta e procura. Os produtos como: café, açúcar, soja, trigo, petróleo, ouro etc., cujo preço pode ser designado pela oferta e procura (internacional).Todo produto produzido em larga escala. Etimologia (origem da palavra commodities): forma plural do inglês commodity." (Dicio, 2017).

Operações futuras são negociações que acontecem com a prefixação de direitos e deveres entre duas ou mais partes, determinando-se preços e quantidades de ativos que terão que ser liquidados em data especifica. "As operações a prazo ocorrem quando compram-se títulos que não são liquidados a vista, mas sim a um prazo predeterminado" (PINHEIRO, 2009, p. 340). Estes contratos comercializados são denominados como Derivativos.

"Podemos conceituar os derivativos como contratos cujos valores e características de negociação estão vinculados aos ativos que lhes servem de referência, ou seja, são ativos financeiros cujos valores dependem (ou derivam) de valores de outras variáveis básicas" (PINHEIRO 2009, p. 340).

Os usos das operações de derivativos protegem o vendedor e comprador, das oscilações de preços do produto na hora da negociação, existem quatro tipos de operações de derivativos, o mercado a termo, mercado a futuro, SWAP e mercado de opções. 
Como afirma Assaf (2015), mercado a termo é uma negociação que os envolvidos, comprador e vendedor, combinam uma determinada quantidade de ativos com preços fixados, e com prazo de quitação combinado em determinada data futura, esse prazo pode atingir 30, 60, 90, 120, 150 e 180 dias, mesmo constando esse estabelecimento de datas, o contrato pode ser liquidado com antecedência deste que o comprador esteja em prol do mesmo.

O mercado a futuro é similar ao mercado a termo, porém podemos o vislumbrar como um mercado a termo evoluído. Nele as partes envolvidas continuam tendo seus direitos e deveres, se comprometendo a arcar com suas obrigações efetivadas na negociação, a diferença que ambos estarão sujeitos aos ajustes diários referentes aos valores do ativo, e os contratos do mercado a futuro só poderão ser negociados nas bolsas de valores.

"A modalidade de negociações futuras transacionadas na Bovespa é o "futuro com ajuste diário de posições", ou seja, todas as posições em aberto serão equalizadas com base no preço de juste do dia, estabelecido para cada papel, com a consequente movimentação diária de débitos e créditos nas contas dos investidores, de acordo com a variação negativa ou positiva no valor de suas posições. " (PINHEIRO, 2009, p. 346).

Os swaps permitem que partes interessadas convertam fluxos de caixas futuros entre si, que se realizam de duas maneiras, sendo: os swaps de taxa de juros, que permutam fluxos de caixas referentes as taxas de juros fixas com alusão a fluxos de caixa de taxa de juros flutuantes, e as swaps de moedas sendo esta responsável pela transação entre moedas diferentes.

"Objetivo: possibilitar ao cliente trocar características de determinada operação com relação a taxas de juros, moedas e prazo, por meio de um contrato. Caracteriza formalmente uma troca de posições para o cliente. Também é muito utilizado como instrumento de proteção com relação aos riscos de mercado (principalmente moeda, taxa e prazo)" (BRITO 2013, p. 122).

No mercado de opções, diferente dos demais já mencionados, não se negociam ativos objetos diretamente, mas sim o direito sobre eles, para simplificar, nas negociações de opções, o titular adquire (compra), um direito que ele pode exercer sobre aquele ativo, porém ele não tem a obrigação de fazer uso do mesmo, podendo assim escolher se deseja usufruir ou não desse direito.

Conforme declara Kerr (2011), existem duas formas de direitos de opções, a opção de compra que pode ser denominada em inglês como call, que permite o titular o direito de comprar o ativo-objeto, pelo preço e quantidade pré-fixados em data futura, e a opção de venda que deriva do inglês put, que assegura seu detentor, de vender seu ativo-objeto em data futura, pelo valor e quantidades fixados.

Hedge e uma ferramenta que gera proteção para quem a utiliza, seu foco não é aumentar ganhos, mas sim prevenir possíveis perdas, sendo uma forma de cessar possíveis riscos existentes nas operações de derivativos.

"Hedger é o agente que faz um hedge, e o ato de fazer hedge é definido como hedging. Segundo o dicionário Michaelis, a palavra hedge, originária desses termos, significa resguardar-se. É exatamente isso que o hedger procura fazer: resguardar-se das variações de preço futuras de um determinado ativo, ou seja, tenta se proteger do risco de mercado", (KERR, 2011, p. 184).

\section{MÉTODOS E PROCESSOS}

Esta pesquisa iniciou com uma pesquisa bibliográfica e se concretizou por meio de uma análise quantitativa comparativa com espaço temporal. 
Na pesquisa bibliográfica identificam-se estudos já realizados sobre o assunto abordado, tendo esses como base de referência para que a nova pesquisa tenha um parâmetro assertivo, ela pode derivar livros, artigos, revistas, matérias da internet.

"A pesquisa bibliográfica é elaborada com base em material já publicado. Tradicionalmente, esta modalidade de pesquisa inclui material impresso, como livros, revistas, jornais, teses, dissertações e anais eventos científicos. Todavia em virtude da disseminação de novos formatos de informação, estas pesquisas passaram a incluir outros tipos de fontes, como discos, fitas magnéticas, CDs, bem como material disponibilizado pela internet" (GIL 2010, p. 29).

Como característica principal pesquisas quantitativas utilizam dados de fácil mensuração, enfatizando uma visão lógica de raciocínio dedutível (GIL 2010).

Os dados coletados em um espaço temporal de cinco anos antecessores, convergem na busca de uma explicação para se obter uma simetria nas negociações da commodity soja, para que os produtores reduzam seus custos e aumentem seus ganhos.

O levantamento bibliográfico para a base teórica desta pesquisa vem dos seguintes autores, Pinheiro 2009, Ernst \& Young 2010, Lozardo 1999, Roberto Borges Kerr 2011, Osias Brito 2013, Alexandre Assaf Neto 2015.

Para a análise teórica será utilizado uma base de dados oficiais, como IBGE, CBOT, BM\&FBovespa, Embrapa e Conab que contribuirão para fazer as devidas comparações de valores e quantidades de comercialização do produto pesquisado.

\section{LEVANTAMENTO DE DADOS}

Na tabela a seguir, podemos identificar a evolução da área cultivada e da produção obtida, em cada período.

Tabela 1: Histórico na produção de soja Brasileira

\begin{tabular}{|l|c|c|cr|}
\hline $\begin{array}{c}\text { Safra } \\
\text { Periodo / ano }\end{array}$ & $\begin{array}{c}\text { Área Cultivada } \\
\text { em milhões de } \\
\text { hectares (ha) }\end{array}$ & $\begin{array}{c}\text { Produção Obtida } \\
\text { em milhões de } \\
\text { toneladas }\end{array}$ & $\begin{array}{c}\text { Valor Médio } \\
\text { Negociado à vista } \\
\text { (Sc 60 kg) }\end{array}$ \\
\hline $2016 / 2017$ & $33.856,00$ & $113.013,04$ & $\mathrm{R} \$$ & 61,29 \\
\hline $2015 / 2016$ & $33.251,90$ & $95.434,60$ & $\mathrm{R} \$$ & 70,97 \\
\hline $2014 / 2015$ & $32.092,90$ & $96.228,00$ & $\mathrm{R} \$$ & 62,97 \\
\hline $2013 / 2014$ & $30.173,10$ & $86.120,80$ & $\mathrm{R} \$$ & 59,17 \\
\hline $2012 / 2013$ & $27.736,10$ & $81.499,40$ & $\mathrm{R} \$$ & 59,10 \\
\hline
\end{tabular}

Fonte: Site Conab (2017); Site Agro link (2017) adaptado pelos autores.

Como se pode observar a uma evolução na área cultivada e na produção de soja no decorrer dos últimos anos, ambos se referem à safra de verão, na qual a leguminosa é plantada em um ano e colhida no próximo, por demonstrando um histórico crescente em ambos, percebesse a sua relevância, os valores descritos foram calculados sobre medias anuais demonstrando as oscilações nos preços no decorrer dos anos. 
Tabela 3 : Calendário Agrícola, Safra Brasileira.

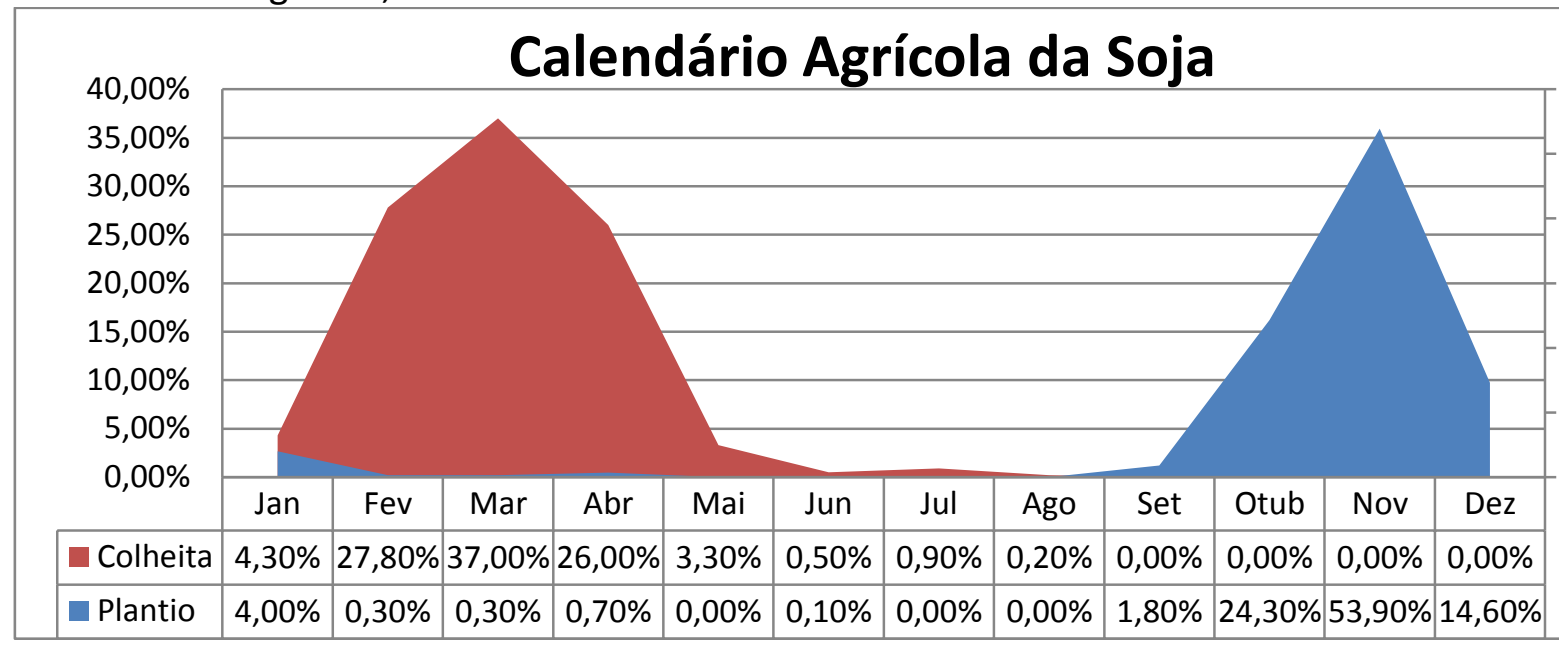

Fonte: Site CONAB (2017) adaptado pelos autores.

Esse é o calendário agrícola Brasileiro da soja, e como o Brasil é um pais continental e obtêm diferentes fases climáticas, consta-se variações de plantio e consequentemente de colheita nos períodos do ano por regiões, o pico do plantio nacional fica entre o mês de outubro e novembro e da colheita entre fevereiro, março e abril.

Tabela 4 : Oscilações do preço nos períodos do ano.

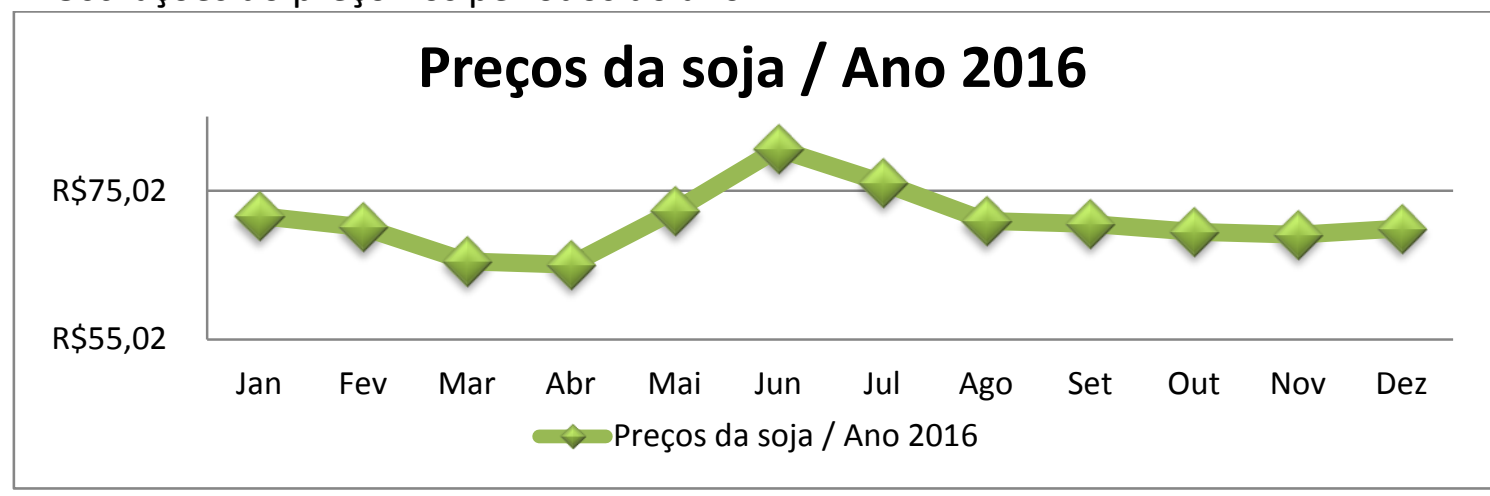

Fonte: Site Agro Link (2017) adaptado pelos autores.

Se comparar a tabela número (4) com a (3), percebe-se que o preço da soja oscila de uma forma parecida com as variações do cultivo da leguminosa, entre safra e safra, de forma que na colheita, quando a oferta aumenta o preço diminui e na entre safra onde os estoques são menores o preço sobe.

\section{RESULTADO}

Esta planilha demonstra a utilização do hedge em períodos de cinco anos antecessores, o preço foi travado em uma data no qual o mesmo se encontra com um preço bom, ocorrendo quase sempre na entre safra. 
Tabela 6: Comparação da Utilização do Hedge.

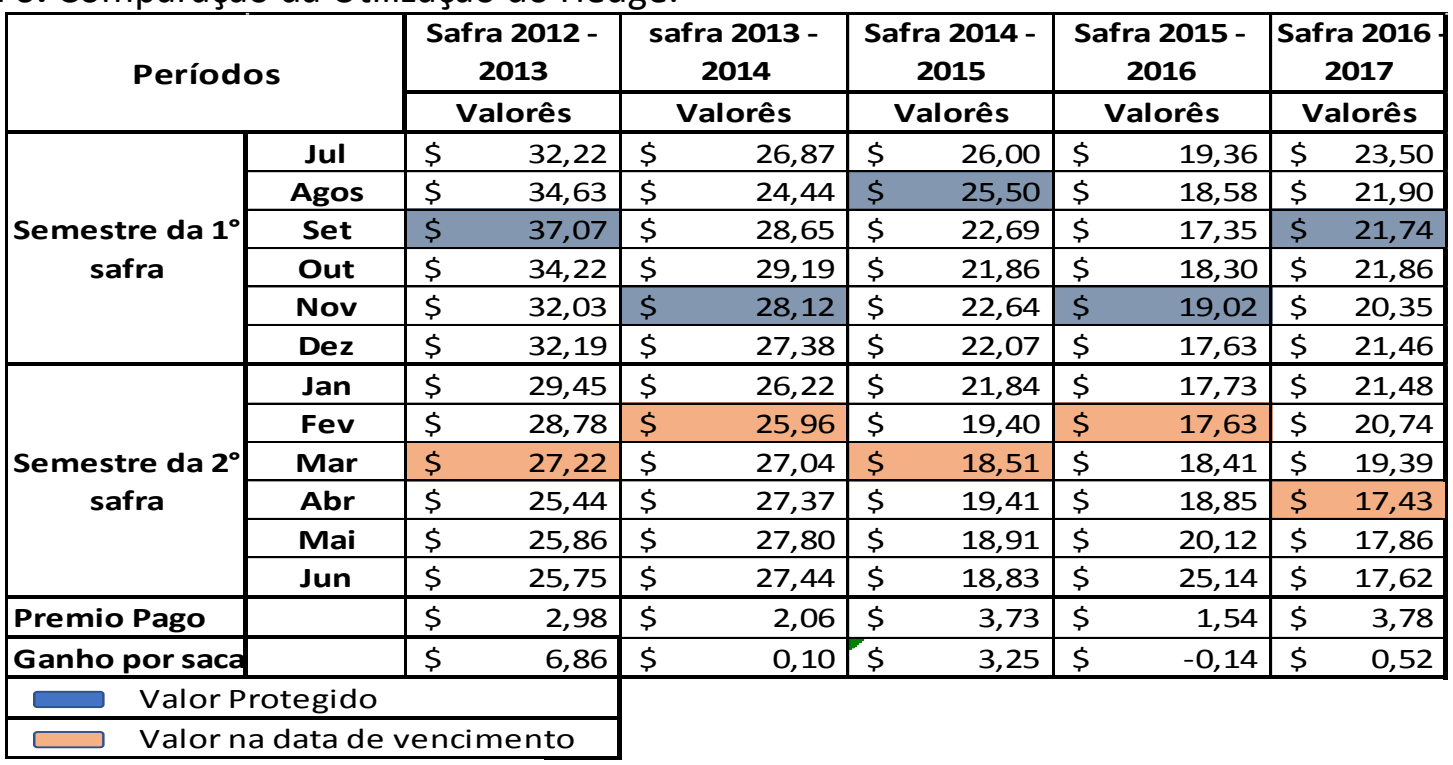

Fonte: Ibovespa 2017 adaptado pelos autores.

No primeiro intervalo analisado, safra 2012 - 2013 observa-se que ocorreu uma queda no preço da soja se comparada com o preço em que se efetuou o hedge, nesse caso o titular exerceu seu direito tendo um ganho de UU\$ 6,86 por saca a mais que se vendesse no mercado a vista, na safra 2013 - 2014 também ocorreu rendimento porém com um valor menor de UU\$ 0,10 por saca, com a safra 2014 - 2015 também obteve-se benefício se comparado o valor protegido com o valor à vista um ganho de UU\$ 3,25 por saca.

Já na safra 2015 - 2016 teve-se uma queda no preço na data futura, porém com uma diferença pequena se comparada com o valor protegido, mesmo assim o titular exerce seu direito porém não vai ter o mesmo ganho que se não tivesse realizado o hedge e vendido no mercado a vista, ele terá que exercer seu direito porque o prémio já foi pago e se ele não o realizar a pecar vai ser maior, assim vendedor vai ter um déficit de UU\$ - 0,14 por saca.

Com a safra 2016 - 2017 o preço caiu se comparado com o valor no qual foi efetuado o hedge, com isso o titular exerce seu direito e obtém um superávit de UU\$ 0,52 por saca se comparado com o valor a vista negociado. Esses valores foram realizados tendo como base produtores com uma propriedade de 50 hectares, que produzem 174 toneladas, que comercializa 121 toneladas com hedge.

\section{CONCLUSÃO}

A utilização do Hedge no mercado de opções em especifico a soja proporciona uma proteção quanto a variações de preços do ativo objeto, uma vez que quase sempre o produtor dessa commodity está oposto a riscos de oscilações no preço, sendo que o mesmo possui um papel fundamental no mercado da soja que por sua vez obtém uma importância em escala nacional e global.

De forma simplificada para se fazer uma operação de Hedge o interessado tem que pagar um prêmio "seguro", o valor deste depende de uma série de variáveis como, prazo de vencimento, preço do ativo objeto, expectativas de oscilações desse preço a verdadeira volatilidade, o titular desse direito saberá se vai exerce essa operação ou não do dia do vencimento, quando fazendo o cálculo valor protegido menos valor de exercício na data de vencimento menos o prêmio pago, se positivo ele exerce seu direito, porém se estiver negativo não o faz uso e vende no mercado avista, perdendo apenas o prêmio. 
A intenção de utilizar o hedge não é aumentar ganhos, mas sim de se proteger contra possíveis variações nos preços que acarretam perdas para o produtor, na pesquisa realizada constatou-se com valores históricos de safras anteriores que a aplicação do hedge compensa para o produtor, sendo que por maior parte os valores ficaram positivos evitando perdas relevantes.

Espera-se que esse estudo possa demonstrar, alertar e orientar produtores da existência de ferramentas de proteção contra variações dos preços de sua maior valia, e que outros acadêmicos interessados no tema venham a exercer pesquisas mais aprofundadas sobre o estudo.

\section{REFERÊNCIAS BIBLIOGRÁFICAS}

KERR, R.; Borges. Mercado financeiro e de capitais. São Paulo: Pearson Prentice, 2011.

PINHEIRO, J.; Lima. Mercado de capitais: fundamentos e técnicas. 5. Ed. São Paulo: Atlas, 2009.

GIL, A.; C. Como elaborar projetos de pesquisa. 5. Ed. São Paulo: Atlas, 2010.

LOZARDO, E. Derivativos no Brasil: fundamentos e práticas. São Paulo: BM\&F, 1998.

ASSAF, A. Neto. Mercado financeiro. 13. Ed. São Paulo: Atlas, 2015.

BRITO, O. Mercado financeiro: estruturas, produtos, serviços, riscos, controle gerencial. 2. Ed. São Paulo: Saraiva, 2013.

DICIO. Dicionário Online de Português. Disponível em: <https://www.dicio.com.br/commoditie/> . Acesso em: 13 mai. 2017.

CONAB. Companhia Nacional de abastecimento. Séries Históricas de Área Plantada, Produtividade e Produção. Disponível em: <http://www.conab.gov.br/conteudos.php?a=1252\&t=2\&Pagina_objcmsconteudos=3\#A_objcmsc onteudos >. Acesso em: 08 mai. 2017.

BM\&FBOVESPA. Disponível em: <http://www.bmfbovespa.com.br/pt_br/ >. Acesso em. 12 maio. 2017.

AGROLINK. 0 Portal do Conteúdo Agropecuário. Disponível em. <https://www.agrolink.com.br/cotacoes/ >. Acesso em. 26 maio. 2017.

FARMNEWS. O canal de notícias da Farmlogics. Disponível em. <http://www.farmnews.com.br/ >. Acesso em 11 julho. 2017.

APROSOJA BRASIL. A Associação dos Produtores de Soja do Brasil. Disponível em. < http://aprosojabrasil.com.br/ >. Acesso em 11 julho. 2017. 